\title{
Microbial Community Structure Drives Predatory Myxobacteria Distribution Under Different Compost Manures
}

\section{Wei Dai}

Institute of Soil Science Chinese Academy of Sciences https://orcid.org/0000-0002-9716-4583

\section{Ning Wang}

CAS Key Laboratory of Soil Environment and Pollution Remediation, Institute of Soil Science, Chinese Academy of Sciences, Nanjing 210008, China

\section{Wenhui Wang}

School of Life Sciences, Anhui Agricultural University, Hefei, Anhui 230036, China

\section{Xianfeng Ye}

Key Laboratory of Agricultural Environmental Microbiology of Ministry of Agriculture, Nanjing Agricultural University, Nanjing 210095, China

\section{Zhongli Cui}

Key Laboratory of Agricultural Environmental Microbiology of Ministry of Agriculture, Nanjing Agricultural University, Nanjing 210095, China

\section{Jieling Wang}

CAS Key Laboratory of Soil Environment and Pollution Remediation, Institute of Soil Science, Chinese Academy of Sciences, Nanjing 210008, China

\section{Dandan Yao}

CAS Key Laboratory of Soil Environment and Pollution Remediation, Institute of Soil Science, Chinese Academy of Sciences, Nanjing 210008, China

\section{Hui Wang ( $\nabla$ hwang@issas.ac.cn )}

CAS Key Laboratory of Soil Environment and Pollution Remediation, Institute of Soil Science, Chinese Academy of Sciences, Nanjing 210008, China

\section{Research Article}

Keywords: Myxobacteria, Manure compost, distribution, Community structure

Posted Date: May 21st, 2021

DOI: https://doi.org/10.21203/rs.3.rs-524148/v1 
License: (c) (i) This work is licensed under a Creative Commons Attribution 4.0 International License. Read Full License 


\section{Abstract}

Myxobacteria are unique predatory microorganisms with a distinct social lifestyle. The associated taxa play key roles in the microbial food webs in different ecosystems and regulate the community structures of soil microbial communities. Compared with conditions under conventional management, under organic conditions, myxobacteria abundance increases in the soil, which could be related to the presence of abundant myxobacteria in the applied compost manure. In the present study, high-throughput sequencing technologies were used to investigate the distribution patterns and drivers of predatory myxobacteria community distribution patterns in four common compost manures. According to the results, there was a significant difference in predatory myxobacteria community structure among different compost manure treatments $(P<0.05)$. The alpha-diversity indices of myxobacteria community under swine manure compost were the lowest (Observed OTU richness $=13.25$, Chao $1=14.83$, Shannon $=0.61$ ), and those under wormcast were the highest (Observed OTU richness $=30.25$, Chao $1=31.65$, Shannon $=2.62$ ). Bacterial community diversity and $\mathrm{Mg}^{2+}$ and $\mathrm{Ca}^{2+}$ concentrations were the major factors influencing myxobacteria distribution patterns under different compost manure treatments. In addition, $\mathrm{pH}$, total nitrogen, and organic carbon influenced myxobacteria distribution in compost manure. The predator-prey relationship between prey bacteria and myxobacteria and the interaction between myxobacteria and specific bacterial taxa (Micrococcales) in compost manure could explain the influence of bacteria on myxobacteria community structure. Further investigations on the in-situ distribution patterns of predatory myxobacteria and the key bacteria influencing their distribution are would advance our understanding of the ecological distribution patterns and functions of predatory microorganisms in the microbial world.

\section{Introduction}

Today, predation is considered a major evolutionary and ecological driver that can influence community structure and ecosystem function[1-3]. Although extensive research has been carried out on predation behavior of large organisms such as animals and plants, predation is much less understood in the microbial world[3]. Myxobacteria are the first taxa of bacteria described as micro-predators, which are capable of secreting antibiotics, hydrolases and bacteriolytic compounds to kill and lyse their prey microorganisms, including bacteria, fungi, protozoa, and other microorganisms[2, 4-6]. Myxobacteria are reportedly highly adaptable cosmopolitans distributed in diverse environments, such as nutrient-rich soil, compost, sand, rocky soil, freshwater lake mud, and the sea[7-10]. However, our understanding of the factors driving the distribution of predatory myxobacteria communities under different environmental conditions remains poor.

Interactions between myxobacteria and prey populations are a key aspect of the microbial food web[11], and predatory myxobacterium controls cucumber Fusarium wilt by regulating soil microbial community structure via decrease modularity and community number and increase connection number per node[12]. In addition, myxobacteria Corallococcus sp. strain EGB can prey on diverse soil bacteria, and could influence microbial community structure in a microcosm system[13]. The accumulation of prey-specific 
predacious genes in myxobacteria genomes partly explains the broad range of myxobacteria prey[14], which makes it reasonable to speculate that the bacterial community structure (composition and abundance) in microbial ecological niches could influence the distribution patterns of myxobacteria communities.

In the Anthropocene, manure, which is mainly excreted by animals or derived from plant residues, is an environmentally friendly soil amendment used to manage soil degradation, and, in turn, increase crop production stability and agroecosystem functioning[15]. Manure application improves soil biochemical properties, such as soil organic carbon, total nitrogen (TN), and microbial biomass carbon[16]. Previous studies have demonstrated that myxobacteria naturally exist in compost manure[10,17, 18], and that the diversity of soil microorganisms and myxobacteria increases under organic farming conditions[19, 20]. In addition, environmental factors could influence the ecological distribution of myxobacteria in soil[21]; however, it is unclear whether the application of compost manure rich in myxobacteria would increase myxobacteria abundance in the soil. In addition, whether environmental factors directly influence the distribution of myxobacteria in compost manure, or indirectly influence myxobacteria distribution via their effects on prey diversity in compost require further investigations.

The aim of the present study was to investigate the factors driving myxobacteria distribution patterns under four common compost manures. The specific objectives were 1) to investigate the distribution patterns of predatory myxobacteria under different compost manures, 2) to explore the abiotic factors influencing the distribution patterns of predatory myxobacteria in compost manure, 3) to explore the correlation between predatory myxobacteria diversity and bacterial community diversity under different compost manures, and 4) to explore the role of predatory myxobacteria in the bacterial community networks in compost manure, and the correlations with associated bacterial groups.

\section{Materials And Methods}

\subsection{Sample collection and analysis}

Four types of compost manure were used in the analyses in the present study. Cow dung (CD, Qingshen Zhongxing Farming Professional Cooperative in Meishan city, Sichuan Province, China), swine manure (SM, Tenghui Farming in Yingtan city, Jiangxi Province, China), and chicken manure (CM, Longxiang Farming in Suqian city, Jiangsu Province, China) samples were collected from commercial composts produced by aerobic fermentation. Wormcast manure (WC) obtained by vermicomposting wormcast for one month, was collected from our laboratory (produced by earthworms ingesting cow dung samples). Each compost manure treatment included four replicates, and the different compost samples were divided into two parts, placed on ice, and transferred to the laboratory. One part was stored at $-20^{\circ} \mathrm{C}$ for use in DNA extraction and microbial analyses. The other part was stored at $4^{\circ} \mathrm{C}$ for use in the determination of compost physicochemical properties. The $\mathrm{pH}, \mathrm{TN}$, organic matter, ammonium-nitrogen $\left(\mathrm{NH}_{4}{ }^{+} \mathrm{N}\right)$, nitrate-nitrogen $\left(\mathrm{NO}_{3}{ }^{-} \mathrm{N}\right)$, total potassium $(\mathrm{TK})$, and total phosphorus (TP) were determined 


\subsection{DNA extraction, 16S rRNA Gene Amplification and MiSeq PE300 sequencing}

DNA was extracted from the samples of the four compost manures stored at $-20^{\circ} \mathrm{C}$ using the FastDNA ${ }^{\circledR}$ Spin Kit for Soil (MP Biomedicals, Santa Ana, CA) according to the manufacturer's instructions. The DNA in the samples was detected by $1 \%$ agarose gel electrophoresis. The V3-V4 hypervariable regions of the bacterial 16S rRNA genes were amplified by PCR using the primers 338F ( $5^{\prime}$ ACTCCTACGGGAGGCAGCAG-3') and 806R (5'-GGACTACHVGGGTWTCTAAT-3'). The PCR products were analyzed on a GeneAmp 9700 PCR system (Applied Biosystems, Foster City, CA, USA). Each sample was amplified in triplicate, and the amplified products were mixed and detected by $2 \%$ agarose gel electrophoresis. Subsequently, purified amplicons were pooled in equimolar amounts and sequenced using an Illumina Miseq PE300 platform (Majorbio-Biopharm Technology, Shanghai, China).

\subsection{Data analysis}

To minimize sequencing errors, low-quality sequences ( $<$ Q30) were first trimmed out using Trimmomatic 0.35[22]. The paired-reads (with minimum 100-bp overlap) were merged and filtered using PANDAseq[23]. Qualified reads were processed using the Quantitative Insights Into Microbial Ecology pipeline[23]. TrimGalore (http://www.bioinformatics.babraham.ac.uk/projects/trim_galore/) and Flash[24] were used to process the final V3-V4 tag sequences. Operational taxonomic units (OTUs) were clustered based on a 97\% similarity cut off using UPARSE (version $7.1 \mathrm{http} / / /$ drive5.com/uparse/) using a novel "greedy" algorithm that performs chimera-filtering and OTU-clustering simultaneously[24]. The taxonomy of each 16S rRNA gene sequence was analyzed using the RDP Classifier algorithm (http://rdp.cme.msu.edu/) against the Silva 16S rRNA database with a confidence threshold of $70 \%$. The sequence numbers in each sample were normalized to the smallest sample size using the"normalized. shared"command in Mothur[25]. High-throughput sequencing data have been deposited in the National Center for Biotechnology Information Sequence Read Archive (BioProject ID PRJNA723459, study accession number SRP14294735-SRP14294746).

\subsection{Predatory myxobacteria community abundance}

Based on the 16S rRNA gene-based OTU results, a total of 682 OTUs annotated as Myxococcales (myxobacteria) at the order level were selected from all the 26412 bacterial OTUs clustered. Predatory myxobacteria community abundance information was obtained based on the abundance information for the 682 myxobacteria OTUs. 


\subsection{Statistical analysis}

The a-diversity (Observed OTU richness, Chao1, Shannon, ACE, and Simpson) of myxobacteria and bacteria were estimated using Mothur[26]. The hierarchical cluster tree was calculated using the "vegan" package in R v 3.5.1(R Foundation for Statistical Computing, Vienna, Austria). Based on the abundance of the bacterial and myxobacteria OTUs, principal coordinate analysis ( $\mathrm{PCOA}$ ) and multivariate regression trees (MRT) were performed and constructed, respectively, using the "vegan" and "mvpart" packages, respectively, in $\mathrm{R} \vee$ 3.5.1 ( $\mathrm{R}$ Foundation for Statistical Computing), Linear regression analysis was used to test the correlation between myxobacteria diversity and bacterial diversity, with sample variety as a random effect, myxobacteria diversity as the dependent variable and bacterial diversity as the independent variable. Analysis of the differences in the abundance of myxobacteria OTUs was performed using the "edgeR" package in R v3.5.1[27]. Network analysis was performed using single/double factor correlation network analysis, and files were generated for network graph visualization using free online platforms, Majorbio I-Sanger Cloud Platform (http://www.i-sanger.com) and MicrobiomeAnalyst (https://www.microbiomeanalyst.ca).

Structural equation modeling (SEM) was used to explore the direct and indirect effects of physicochemical parameters and bacterial community diversity on myxobacteria community structure using the "lavaan" package in R v3.5.1[28]. Our SEM analysis included six variables: myxobacteria diversity, bacterial diversity, $\mathrm{pH}, \mathrm{TN} \mathrm{Mg}^{2+}$, and $\mathrm{Ca}^{2+}$. Distributions of myxococcales in the four types of manure compost were assessed using the "vcd" package in R v 3.5.1 and Circos (http://circos.ca/). Other statistical analyses were conducted using SPSS 13.0 (SPSS Inc., Chicago, IL, US).

\section{Results}

\subsection{Bacteria and myxobacteria diversity and abundance in different compost manures}

In the present study, a total of 762,476 high-quality bacterial and 20,210 myxobacteria sequences were obtained after quality control filtering and removal of potential chimeras. The number of bacteria and myxobacteria 16 S rRNA sequences per sample ranged from 21,767 to 778,182 , and 762 to 2140 , respectively. Based on $97 \%$ sequence similarity, bacterial and myxobacteria sequences were clustered into 26,412 and 682 OTUs, respectively. Bacterial sequences were primarily composed of the phyla Proteobacteria (32\%), Bacteroidetes (25\%), Actinobacteria (13\%), Chloroflexi (9\%), Acidobacteria (8\%), and Firmicutes (5.8\%). Conversely, the majority of myxobacteria sequences, in addition to the unassigned OTUs, belonged to the family Haliangiaceae (37\%), OM27 (5\%), Polyangiaceae (4\%), and Nannocystaceae (2\%) (Figure S1).

Alpha-diversity indices (Observed OTU richness, Chao1, and Shannon diversity) values for bacterial and myxobacteria communities in different compost manures are illustrated in Figure 1. One-way Analysis of Variance results showed that the compost manures altered bacterial and myxobacteria community 
diversity and abundance significantly $(P<0.05)$ (Figure 1 , Table S1). The relative abundance and diversity of bacteria differed significantly among the four types of compost manure $(P<0.05)$ (Table S1). In the case of myxobacteria communities, the alpha-diversity indices were the lowest in SM (Observed OTU richness $=13.25$, Chao1 $=14.83$, Shannon $=0.61)$, and the highest in WC (Observed OTU richness $=$ 30.25 , Chao1 $=31.65$, Shannon $=2.62$ ). Although myxobacteria abundance in CM was higher than that in $\mathrm{CD}$, myxobacteria diversity exhibited opposite trends in the two compost manures (Figure 1B). In addition, myxobacteria abundance and diversity trends in all four types of compost manure were similar to those of bacteria (Figure $1 \mathrm{~A})$.

\subsection{Myxobacteria Community Structure Among the Four Compost Manures}

Based on the relative abundances of bacteria in different compost manures, the main bacterial orders in all samples were Micrococcales, Xanthomonadales, Clostridiales, Anaerolineales, Flavobacteriales, Rhizobiales, Sphingobacteriales, Pseudomonadales, and Myxococcales (Figure S1). Myxococcales was a major taxa in the bacterial communities, accounting for approximately $3.15 \%$ of the total bacteria in the four types of compost manure.

At the family level, within the myxobacteria communities, the dominant families (merging small taxa with counts $<10$, Figure 2A) across the four types of compost manure were Haliangiaceae (37\%), OM27 (5\%), Polyangiaceae (4\%), and Nannocystaceae (2\%). Haliangiaceae abundance in the CD and SM was higher than those in the other two compost manure types. Conversely, Polyangiaceae relative abundance was the highest in $\mathrm{CD}$. At the order level, the relative abundance of Myxococcales was significantly different among the four types of compost manure $(P<0.05)$ (Figure 2B, Table S2), while CD had the highest abundance $(\mathrm{CD}>\mathrm{WC}>\mathrm{CM}>\mathrm{SM}, 74 \%>19 \%>6.1 \%>0.78 \%)$.

According to the PCoA (carried out based on Bray-Curtis distances) plots (Figure 3A) and Dendrogram Analysis (carried out based on Bray-Curtis distances) results (Figure 3B), myxobacteria community structure was significantly different among the four types of compost manure $(P<0.05)$ (Table S2). In the first component of the PCoA analysis (PCOA1), the community structures in $\mathrm{CM}$ and WC were rather similar, and the hierarchical clustering trees showed similar results (Figure 3 ).

\subsection{Correlations Between Myxobacteria and Bacterial Community Diversity}

The community distribution of myxobacteria in compost manure was influenced significantly by bacterial community diversity. There were significant and positive linear correlations between myxobacteria and bacterial community diversity ( $\alpha$ - and $\beta$-diversity) in the four types of compost manure (Figure $4, P<$ 0.0001). The PCoA1 axes of myxobacteria abundance and bacteria abundance showed significant linear 
relationships with each other (Figure $4 A, R^{2}=0.9986, P<0.0001$ ), and, among the multiple diversity indices, there were consistent results with regard to Shannon diversity between myxobacteria and bacteria (Figure 4B, $\mathrm{R}^{2}=0.94411, \mathrm{P}<0.0001$ ).

\subsection{Correlation between myxobacteria community diversity and composition, and environmental parameters}

To investigate whether there was a relationship between OTU-level myxobacteria community structure and the physicochemical properties of the compost manures, MRT analysis was performed and visualized based on a tree with four splits based on $\mathrm{Ca}^{2+}$ and $\mathrm{Mg}^{2+}$ concentrations (Figure5A). The tree explained $91.13 \%$ of the variance in myxobacteria composition among the four types of compost manures (Table S3). The histograms at the four nodes of the tree illustrate an overview of the myxobacteria community structure. Myxobacteria community composition was first split by $\mathrm{Mg}^{2+}$ (threshold value $1.915 \mathrm{~g} \cdot \mathrm{kg}^{-1}$ ), which explained $75.76 \%$ of the variation. The Group represents a group of compost manure samples under the split. Group 1 and Group 2, with eight manure compost samples had $\mathrm{Mg}^{2+}$ concentrations $<1.915 \mathrm{~g} \cdot \mathrm{kg}^{-1}$, and the other eight compost manure samples in Groups 3, 4, and 5 had $\mathrm{Mg}^{2+}$ concentrations $>1.915 \mathrm{~g} \cdot \mathrm{kg}^{-1}$. Manure compost $\mathrm{Ca}^{2+}$ concentrations (threshold value 1.185 $\mathrm{g} \cdot \mathrm{kg}^{-1}$ ) further split the eight manure composts samples into two branches, and explained $8.25 \%$ of the variation. Group 1 contained four compost manure samples with $\mathrm{Ca}^{2+}$ concentrations $>1.185 \mathrm{~g}^{\mathrm{kg}}{ }^{-1}$, in which Haliangiaceae abundance was $81.2 \%$, followed by Unclassified (15.4\%), and Polyangiaceae (1.4\%). Groups 2 contained four manure compost samples with $\mathrm{Ca}^{2+}<1.185 \mathrm{~g}^{\mathrm{kg}} \mathrm{g}^{-1}$, in which Haliangiaceae abundance was $43.8 \%$, followed by Unclassified (38.2\%) and Polyangiaceae (9.2\%). The third split the eight compost manure samples into two branches and explained $5.66 \%$ of the variation. Groups 3 , 4 , and 5 with $\mathrm{Mg}^{2+}$ concentrations $>1.915 \mathrm{~g} \cdot \mathrm{kg}^{-1}$ were finally split by $\mathrm{Mg}^{2+}$ (threshold value $2.92 \mathrm{~g} \cdot \mathrm{kg}^{-1}$ ) and $\mathrm{Ca}^{2+}$ (threshold value $4.09 \mathrm{~g} \mathrm{~kg}^{-1}$ ) contents, which jointly explained $7.12 \%$ of the variation. In Group 3, the predominant bacterial taxa were Unclassified (88.8\%), Haliangiaceae (2.6\%), and Nannocystaceae (2.2\%), and the predominant bacterial taxa in Group 4 were Unclassified (65.0\%), OM27 (17.4\%), and Haliangiaceae (6.0\%). Among all the bacterial taxa, the abundance of Haliangiaceae, OM27 and Nannocystaceae were the most influenced by $\mathrm{Mg}^{2+}$ and $\mathrm{Ca}^{2+}$ concentrations in compost manure (Table S4).

The relationship between myxobacteria community diversity and environmental factors was also illustrated based on MRT analysis results, with four splits based on $\mathrm{TP}, \mathrm{OC}, \mathrm{TK}$, and $\mathrm{NO}_{3}{ }^{-} \mathrm{N}$ (Fig. 5B, Table S3). The tree accounted for $95.99 \%$ of the variation in the standardized diversity indices. TP split the 16 compost manure samples into two branches with different diversity patterns, including fours samples in Groups 1 with TP $\geq 12.43 \mathrm{~g} \cdot \mathrm{kg}^{-1}$ and 12 samples in Groups 2, 3, 4, and 5 with TP $<12.43 \mathrm{~g} \cdot \mathrm{kg}-1$. Samples with relatively low TP $(<12.43 \mathrm{~g} \cdot \mathrm{kg}-1)$ had relatively high diversity indices (Observed OTU richness, Chao1, Shannon, ACE, and Simpson). The two branches were further split by OC, and relatively high 
diversity indices were observed in samples with relatively low OC. Similar to OC, TP explained $90.61 \%$ of the variation. $\mathrm{TK}$ and $\mathrm{NO}_{3}-\mathrm{N}$ further influenced bacterial diversity among four compost manures and explained $5.38 \%$ of the variation. Overall, the compost manures with relatively high $\mathrm{TK}$ and $\mathrm{NO}_{3}{ }^{-} \mathrm{N}$ contents had relatively high diversity indices.

\subsection{Network analysis and structural equation modeling of myxobacteria community structure in compost manures}

An ecological network illustrates the interaction of various organisms in an ecosystem. In the correlation network in the present study, the symbiotic relationship between myxobacteria and other bacteria drove the ecological network topology. As illustrated in Figure 6A, a single factor correlation network with 20 nodes was constructed based on the four types of compost manure under study (Table S5). In the network, myxobacteria and other bacteria (order level) formed a complex topological network structure (absolute value of Spearman's correlation coefficient $\geq 0.6$ ). The Myxococcales node had a relatively high degree and clustering coefficient, and co-occurred with some nutrition-related bacteria; Myxococcales had a significant and positive correlation with bacterial orders (Cellvibrionales, Sphingomonadales, Flavobacteriales, Burkholderiales, Cytophagales, Rhodospirillales, and Rhizobiales), and a significant and negative correlation with Micrococcales (Figure S3).

According to the results of two-factor correlation network analysis, the abundance of myxobacteria was significantly related to various environmental factors. In the four types of compost manure, $\mathrm{Na}^{+}, \mathrm{TN}^{\mathrm{T}}$, and TK concentrations were significantly and positively correlated with Myxococcale abundance; conversely, $\mathrm{OC}, \mathrm{Ca}^{2+}$, and $\mathrm{NH}_{4}{ }^{+}-\mathrm{N}$ concentrations were significantly and negatively correlated with Myxococcale abundance, which are consistent with the results of the MRT analysis.

According to the SEM results, bacterial diversity, $\mathrm{Mg}^{2+}$ concentrations, and $\mathrm{pH}$ positively influenced myxobacteria diversity, while $\mathrm{Ca}^{2+}$ concentration had an opposite effect. In addition, metal ions had potentially varied effects on the diversity of different microorganisms in compost manure. For example, $\mathrm{Ca}^{2+}$ had a positive effect on bacterial diversity, and a negative effect on myxobacteria diversity. Overall, our model explained $95.9 \%$ of the variation in myxobacteria diversity.

\section{Discussion}

Soil bacteria biogeography could reveal significant correlations between bacterial community distribution and environmental factors[29]. Moreover, microorganism distribution and development are influenced by complex interactions with plants, animals, and other microbes, which could have beneficial, neutral, or harmful effects on bacterial community members[6]. In the present study, we investigated the distribution of predatory myxobacteria in microbial communities in different compost manures. Overall, the results 
indicated that bacterial community diversity, $\mathrm{Mg}^{2+}$ and $\mathrm{Ca}^{2+}$ concentrations, and $\mathrm{pH}$ were associated with myxobacteria community diversity in different compost manures.

\subsection{Myxobacteria Community Structure in Different Compost Manures}

Myxobacteria are mainly distributed in soil environments and most predatory myxobacteria are isolated from agricultural soils[2]. Compared with conventional farming, organic farming with organic fertilizer amendment can enhance microbial diversity and richness[19]. The application of organic fertilizer can significantly increase the diversity and richness of myxobacteria in the soil[20]. According to a previous study, myxobacteria in a single soil sample accounted for $4.1 \%$ of the entire bacterial community[21], and Myxococcale sequences accounted for $1.31-4.17 \%$ of the sequences in $16 \mathrm{~S}$ rRNA gene libraries in the four types of compost manure examined in the present study. The relative abundance of myxobacteria in farmland soils[19] and subtropical and tropical forest soils[6] have been reported to account for 0.36$4.10 \%$ and $1.49-4.74 \%$ of the total bacterial abundance, respectively, which are consistent with the results reported in the present study under compost manure.

Myxobacteria were unevenly distributed in different compost manures, and not all myxobacteria families could be observed in the samples examined; particularly, Myxococcaceae and Cystobacteraeae were not observed in some samples. Cystobacterineae are frequently isolated from environments using culturedependent methods[30]; however, according to our results, Cystobacterineae abundance in the different compost manures was low, potentially highlighting the bias of the culture-independent method.

Researchers have reported that Sorangium can secrete high amounts of cellulose-degrading enzymes[31]. In the present study, Sorangium had high relative abundance in the CM compost, which could be associated with the high cellulose amount in the CM compost. In addition, in the present study, myxobacteria diversity in WC manure was significantly higher than that in SM. This could be because compared to SM, WC contains more easily usable organic substances[32], and higher microbial diversity and abundance[33], which provides adequate food and a suitable environment for myxobacteria development and survival.

\subsection{Effects of Abiotic Factors on Myxobacteria Community Structure in Compost Manure}

According to previous reports, microbial community structure is mainly influenced by environmental factors[34], and soil characteristics are correlated with myxobacteria abundance[21]. Similarly, myxobacteria distribution in the different compost manures in the present study was influenced by abiotic factors. We also observed correlations between abiotic factors of compost manure and 
myxobacteria community structure. In addition, according to the SEM results, abiotic factors of manure compost influenced myxobacteria community structure directly.

According to the results of the present study, abiotic factors significantly influence the distribution patterns of predatory myxobacteria in different compost manures. Specifically, $\mathrm{pH}, \mathrm{TN}$ concentration, and $\mathrm{Mg}^{2+}$ concentration are significantly positively correlated with myxobacteria community diversity; conversely, $\mathrm{Ca}^{2+}$ and $\mathrm{NH}_{4}{ }^{+}-\mathrm{N}$ concentrations in compost manure were significantly and negatively correlated with myxobacteria community diversity. $\mathrm{pH}$ is the major abiotic factor influencing the distribution of microorganisms in different environments[35-38]. Similarly, pH considerably influenced myxobacteria distribution in compost manure in the present study. Myxobacteria are mostly distributed in environments with a $\mathrm{pH}$ of approximately $6.5-8.5$, especially in neutral to weakly alkaline soils with $\mathrm{pH}$ 6.0-8.0[39, 40]. Excluding in the case of $\mathrm{CD}(\mathrm{pH} 9.21-9.47)$, the $\mathrm{pH}$ values of the other three compost manures ( $\mathrm{pH} 7.09-7.82)$ were all within the optimal range for the myxobacteria survival, which could explain the high myxobacteria abundance in the three compost manures. $\mathrm{NH}_{4}{ }^{+} \mathrm{N}$ is the preferred nitrogen source for most microorganisms[41]. Therefore, $\mathrm{NH}_{4}{ }^{+}-\mathrm{N}$ could positively influence bacterial community structure when agricultural waste compost is adopted as fertilizer[34]; however, in the present study, we observed that myxobacteria abundance in compost manure was significantly negatively correlated with $\mathrm{NH}_{4}{ }^{+}-\mathrm{N}$ concentration, which is similar to results on the distribution of predatory bacteria in soil[20].

Salt ion concentrations can influence the growth and development of myxobacteria[42-45]. $\mathrm{Mg}^{2+}$ and $\mathrm{Ca}^{2+}$ concentrations are generally considered to promote myxobacteria development $[46,47]$. Notably, in the present study, $\mathrm{Mg}^{2+}$ concentrations in different compost manures were positively correlated with myxobacteria diversity, while opposite trends were observed with regard to $\mathrm{Ca}^{2+}$ concentrations. Based on the SEM analysis results, $\mathrm{Mg}^{2+}$ not only had a positive effect on myxobacteria diversity in different compost manures but also indirectly influenced myxobacteria diversity by affecting bacterial diversity.

In the present study, high $\mathrm{Ca}^{2+}$ concentrations were the major reason for the decrease in myxobacteria diversity in the four types of compost manure, with $\mathrm{Ca}^{2+}$ concentration being negatively correlated with myxobacteria diversity; however, it can positively affect bacterial diversity in the four types of compost manure. In addition, the complex interactions between myxobacteria and indigenous microorganisms cannot be overlooked. High concentrations of $\mathrm{Ca}^{2+}$ could promote the growth of some bacteria antagonistic to myxobacteria and, in turn, influence myxobacteria diversity. According to our results, high $\mathrm{Ca}^{2+}$ concentrations were significantly and positively correlated with Micrococcales abundance, while Micrococcales abundance was significantly and negatively correlated with Myxococcales abundance and diversity, which is partly consistent with our speculation.

\subsection{Effect of Manure Compost bacterial diversity on Myxobacteria Community Structure}


Microbial interactions such as auxotrophies and nutrient demands among members of a microbial community are key drivers of microbial community structure[48]. As a major class of predatory bacteria in microbial communities, myxobacteria can prey on gram-negative and gram-positive bacteria, yeasts, fungi, protozoa, and nematodes[2, 49]. We observed significant correlation between myxobacteria diversity and bacterial community composition under different compost manures. Although no causal relationship was established, the results revealed direct correlation between potential prey and predators at the community level.

Because soil myxobacteria cannot synthesize riboflavin and branched-chain amino acids[3], their community structures could be influenced by prey availability. In the present study, there was a positive correlation between the relative abundance of bacteria and the relative abundance of myxobacteria in compost manure. Considering predation of myxobacteria on prey bacteria, the reason for the increase in myxobacteria abundance is potentially an increase in the number of prey bacterial cells. Notably, some researchers have reported that Corallococcus sp. EGB strains control cucumber wilt disease by migrating to plant roots and regulating soil microbial community structure at the sites[12]. Consistent with our results, other studies on predator-prey diversity relations have reported positive correlation between predator abundance and prey abundance[50-52]. To the best of our knowledge, this is the first study to explore the relationship between predatory myxobacteria and bacterial community structure across different types of compost manure.

Preferential predation by micro-predators could explain the influence of bacterial communities on predatory microbial community structure. According to the results of the single-factor correlation network analysis in the present study, in the microbial correlation network of the different compost samples, Myxococcales were significantly positively correlated with Sphingomonadales, Flavobacteriales, Cellvibrionales, Cytophagales, Burkholderiales, Rhizobiales, and Rhodospirillales (order level), which implies potential predator-prey relationships. The gram characteristics of prey bacteria could influence prey selection by myxobacteria. Myxococcus are reportedly more supported by gram-negative prey than by gram-positive bacteria[53]. We also note that in the present study, Myxococcales nodes in the correlation network were significantly and positively correlated with gram-negative bacteria, and significantly and negatively correlated with gram-positive bacteria (Micrococcales). However, the overall conclusion that gram-negative prey can more effectively support Myxococcales requires further investigation and evidence. Other studies have also reported that Haliangiaceae are effectively supported by Arthrobacter globiformis (a gram-positive actinomycete)[5]. In the present study, we highlight the influence of bacterial community structure on myxobacteria community distribution patterns in different compost manures. Nevertheless, the key bacterial taxa driving the distribution patterns of myxobacteria require further investigations.

\section{Conclusions}

In the present study, we reveal the key factors influencing myxobacteria distribution in different compost manures for the first time. We report that abiotic factors $\left(\mathrm{pH}\right.$ and $\mathrm{Mg}^{2+}$ ) have positive effects on of 
myxobacteria community diversity as well as bacterial community diversity. However, high $\mathrm{Ca}^{2+}$ concentrations have negative effects on myxobacteria diversity. Overall, bacterial community diversity and $\mathrm{Mg}^{2+}$ and $\mathrm{Ca}^{2+}$ were the major factors influencing myxobacteria distribution in different compost manures. Nevertheless, due to the complex predator-prey interactions, our data failed to determine the specific bacterial groups influencing the myxobacteria distribution in the compost manures. Our findings could facilitate the selection of appropriate compost manure types and appropriate management soil management strategies based on the physicochemical properties of the compost, which could not only increase myxobacteria community diversity and abundance in manure compost but also enhance soil health in farmland amended with organic fertilizer.

\section{Declarations}

\section{Acknowledgments}

We are grateful for the computation resources from the High-Performance Computing System at National Engineering Laboratory of Soil Pollution Control and Remediation Technologies, CAS Key Laboratory of Soil Environment and Pollution Remediation, Institute of Soil Science, Chinese Academy of Sciences."

This work was financially supported by the National Natural Science Foundation of China (42077034), National Key Research and Development Project (2016YFD0200309), and Local GovernmentCommissioned Project from Mangshi, Yunnan (CN) (201906DHHCFW2020028).

Funding: This work was financially supported by the National Natural Science Foundation of China (42077034), National Key Research and Development Project (2016YFD0200309), and Local Government-Commissioned Project from Mangshi, Yunnan (CN) (201906DHHCFW2020028).

Conflicts of interest/Competing interests: The authors declare that they have no known competing financial interests or personal relationships that could have appeared to influence the work reported in this paper.

Availability of data and material: The datasets analysed during the current study are available in the NCBI Sequence Read Archive (SRA) repository, BioProject ID PRJNA723459, study accession number SRP14294735-SRP14294746.

Code availability: All data generated or analyzed during this study are included in this published article and its supplementary information files.

Authors' contributions: All authors contributed to the study conception and design. Material preparation, data collection and analysis were performed by Wei Dai, Ning Wang, Jieling Wang and Dandan Yao. The first draft of the manuscript was written by Wei Dai and all authors commented on previous versions of the manuscript. All authors read and approved the final manuscript.

Ethics approval: Not applicable 
Consent to participate: Informed consent was obtained from all individual participants included in the study.

Consent for publication: Additional informed consent was obtained from all individual participants for whom identifying information is included in this article.

\section{References}

1. Schmitz OJ (2007) Predator diversity and trophic interactions. Ecology 88: 2415-2426. doi: 10.1890/06-0937.1

2. Perez J, Moraleda-Munoz A, Marcos-Torres FJ, Munoz-Dorado J (2016) Bacterial predation: 75 years and counting! Environ Microbiol 18: 766-779. doi: 10.1111/1462-2920.13171

3. Pasternak Z, Pietrokovski S, Rotem O, Gophna U, Lurie-Weinberger MN, Jurkevitch E (2013) By their genes ye shall know them: genomic signatures of predatory bacteria. ISME J 7: 756-769. doi: 10.1038/ismej.2012.149

4. José M-D, J M-TF, Elena G-B, Aurelio M-M, Juana P (2016) Myxobacteria: Moving, Killing, Feeding, and Surviving Together. \%J Frontiers in microbiology7.

5. Lu Z, Tillmann L (2017) Micropredator niche differentiation between bulk soil and rhizosphere of an agricultural soil depends on bacterial prey. \%J FEMS microbiology ecology93.

6. Zhou Y, Zhang X, Yao Q, Zhu H (2020) Both Soil Bacteria and Soil Chemical Property Affected the Micropredator Myxobacterial Community: Evidence from Natural Forest Soil and Greenhouse Rhizosphere Soil. Microorganisms 8. doi: 10.3390/microorganisms8091387

7. Kou W, Zhang J, Lu X, Ma Y, Mou X, Wu L (2016) Identification of bacterial communities in sediments of Poyang Lake, the largest freshwater lake in China. Springerplus 5: 401. doi: 10.1186/s40064-0162026-7

8. Mohr KI, Stechling M, Wink J, Wilharm E, Stadler M (2016) Comparison of myxobacterial diversity and evaluation of isolation success in two niches: Kiritimati Island and German compost. Microbiologyopen 5: 268-278. doi: 10.1002/mbo3.325

9. Powell JT, Chatziefthimiou AD, Banack SA, Cox PA, Metcalf JS (2015) Desert crust microorganisms, their environment, and human health \%J Journal of Arid Environments112.

10. Singh BN (1947) Myxobacteria in soils and composts; their distribution, number and lytic action on bacteria. J Gen Microbiol 1: 1-10. doi: 10.1099/00221287-1-1-1

11. Lueders T, Kindler R, Miltner A, Friedrich MW, Kaestner M (2006) Identification of bacterial micropredators distinctively active in a soil microbial food web. Applied and Environmental Microbiology 72: 5342-5348. doi: 10.1128/aem.00400-06

12. Ye X, Li Z, Luo X, Wang W, Li Y, Li R, Zhang B, Qiao Y, Zhou J, Fan J, Wang H, Huang Y, Cao H, Cui Z, Zhang R (2020) A predatory myxobacterium controls cucumber Fusarium wilt by regulating the soil microbial community. Microbiome 8: 49. doi: 10.1186/s40168-020-00824-x 
13. Dai W, Jiu M, Wang W, Cui Z, Wang H (2020) Effects of myxobacteria predation on microbial community structure of artificial microcosm. Acta Microbiologica Sinica 60: 452-463.

14. Sutton D, Livingstone PG, Furness E, Swain MT, Whitworth DE (2019) Genome-Wide Identification of Myxobacterial Predation Genes and Demonstration of Formaldehyde Secretion as a Potentially Predation-Resistant Trait of Pseudomonas aeruginosa. Frontiers in Microbiology 10. doi: 10.3389/fmicb. 2019.02650

15. Liu S, Wang J, Pu S, Blagodatskaya E, Kuzyakov Y, Razavi BS (2020) Impact of manure on soil biochemical properties: A global synthesis. Sci Total Environ 745: 141003. doi: 10.1016/j.scitotenv.2020.141003

16. Luo G, Li L, Friman V-P, Guo J, Guo S, Shen Q, Ling N (2018) Organic amendments increase crop yields by improving microbe-mediated soil functioning of agroecosystems: A meta-analysis. Soil Biology \& Biochemistry 124: 105-115. doi: 10.1016/j.soilbio.2018.06.002

17. Sanford RA, Cole JR, Tiedje JM (2002) Characterization and description of Anaeromyxobacter dehalogenans gen. nov., sp. nov., an aryl-halorespiring facultative anaerobic myxobacterium. Appl Environ Microbiol 68: 893-900. doi: 10.1128/aem.68.2.893-900.2002

18. Tanahashi T, Murase J, Matsuya K, Hayashi M, Kimura M, Asakawa S (2005) Bacterial Communities Responsible for the Decomposition of Rice Straw Compost in a Japanese Rice Paddy Field Estimated by DGGE Analysis of Amplified 16S rDNA and 16S rRNA Fragments \%J Soil Science and Plant Nutrition51.

19. Wang W, Wang H, Feng Y, Wang L, Xiao X, Xi Y, Luo X, Sun R, Ye X, Huang Y, Zhang Z, Cui Z (2016) Consistent responses of the microbial community structure to organic farming along the middle and lower reaches of the Yangtze River. Sci Rep 6: 35046. doi: 10.1038/srep35046

20. Wang W, Luo X, Ye X, Chen Y, Wang H, Wang L, Wang Y, Yang Y, Li Z, Cao H, Cui Z (2020) Predatory Myxococcales are widely distributed in and closely correlated with the bacterial community structure of agricultural land. Applied Soil Ecology 146. doi: 10.1016/j.apsoil.2019.103365

21. Zhou X-w, Li S-g, Li W, Jiang D-m, Han K, Wu Z-h, Li Y-z (2014) Myxobacterial community is a predominant and highly diverse bacterial group in soil niches. Environmental Microbiology Reports 6: 45-56. doi: 10.1111/1758-2229.12107

22. M BA, Marc L, Bjoern U (2014) Trimmomatic: a flexible trimmer for Illumina sequence data. \% J Bioinformatics (Oxford, England) 30.

23. Masella AP, Bartram AK, Truszkowski JM, Brown DG, Neufeld JD (2012) PANDAseq: paired-end assembler for illumina sequences \%J BioMed Central13.

24. Mago T, ccaron, Salzberg SL (2011) FLASH: fast length adjustment of short reads to improve genome assemblies \%J Bioinformatics27.

25. D SP, L WS, Thomas R, R HJ, Martin H, B HE, A LR, B OB, H PD, J RC, W SJ, Blaz S, G TG, J VHD, F WC (2009) Introducing mothur: open-source, platform-independent, community-supported software for describing and comparing microbial communities. \% J Applied and environmental microbiology 75. 
26. D SP, Dirk G, L WS (2011) Reducing the effects of PCR amplification and sequencing artifacts on $16 S$ rRNA-based studies. \%J PloS one6.

27. Robinson MD, McCarthy DJ, Smyth GK (2010) edgeR : a Bioconductor package for differential expression analysis of digital gene expression data \%J Bioinformatics26.

28. Jorgensen TD, Jak S (2020) Review of Gana \& Broc's Structural Equation Modeling with lavaan. Psychometrika 85: 373-377. doi: 10.1007/s11336-020-09705-6

29. Griffiths RI, Thomson BC, James P, Bell T, Bailey M, Whiteley AS (2011) The bacterial biogeography of British soils. Environ Microbiol 13: 1642-1654. doi: 10.1111/j.1462-2920.2011.02480.x

30. Garcia R, Prokaryotes RMJT (2014) The Family Myxococcaceae.

31. Hou P-b, Li Y-z, Wu B-h, Yan Z-c, Yan B-x, Gao P-j (2006) Cellulolytic complex exists in cellulolytic myxobacterium Sorangium. Enzyme and Microbial Technology 38: 273-278. doi:

10.1016/j.enzmictec.2004.08.044

32. Chen M, Xu Y (2014) Influence of the Assorted Usage of Wormcast and Pig Manure Compost on the Composition Change of Humus and Yield. Acta Agriculturae Boreali-Sinica 29: 233-238.

33. Lv B, Xing M, Yang J, Zhang L (2015) Pyrosequencing reveals bacterial community differences in composting and vermicomposting on the stabilization of mixed sewage sludge and cattle dung. Applied Microbiology and Biotechnology 99: 10703-10712. doi: 10.1007/s00253-015-6884-7

34. Wang X, Cui H, Shi J, Zhao X, Zhao Y, Wei Z (2015) Relationship between bacterial diversity and environmental parameters during composting of different raw materials. Bioresour Technol 198: 395402. doi: 10.1016/j.biortech.2015.09.041

35. Davison J, Moora M, Semchenko M, Adenan SB, Ahmed T, Akhmetzhanova AA, Alatalo JM, AlQuraishy S, Andriyanova E, Anslan S, Bahram M, Batbaatar A, Brown C, Bueno CG, Cahill J, Cantero JJ, Casper BB, Cherosov M, Chideh S, Coelho AP, Coghill M, Decocq G, Dudov S, Fabiano EC, Fedosov VE, Fraser L, Glassman SI, Helm A, Henry HAL, Herault B, Hiiesalu I, Hiiesalu I, Hozzein WN, Kohout P, Koljalg U, Koorem K, Laanisto L, Mander U, Mucina L, Munyampundu J-P, Neuenkamp L, Niinemets U, Nyamukondiwa C, Oja J, Onipchenko V, Partel M, Phosri C, Polme S, Pussa K, Ronk A, Saitta A, Semboli O, Sepp S-K, Seregin A, Sudheer S, Pena-Venegas CP, Paz C, Vahter T, Vasar M, Veraart AJ, Tedersoo L, Zobel M, opik M (2021) Temperature and pH define the realised niche space of arbuscular mycorrhizal fungi. New Phytologist. doi: 10.1111/nph.17240

36. Jiang C, Peces M, Andersen MH, Kucheryavskiy S, Nierychlo M, Yashiro E, Andersen KS, Kirkegaard RH, Hao L, Hogh J, Hansen AA, Dueholm MS, Nielsen PH (2021) Characterizing the growing microorganisms at species level in 46 anaerobic digesters at Danish wastewater treatment plants: A six-year survey on microbial community structure and key drivers. Water research 193: 116871116871. doi: 10.1016/j.watres.2021.116871

37. Machado de Lima NM, Munoz-Rojas M, Vazquez-Campos X, Zanini Branco LH (2021) Biocrust cyanobacterial composition, diversity, and environmental drivers in two contrasting climatic regions in Brazil. Geoderma 386. doi: 10.1016/j.geoderma.2020.114914 
38. Pollierer MM, Scheu S (2017) Driving factors and temporal fluctuation of Collembola communities and reproductive mode across forest types and regions. Ecology and Evolution 7: 4390-4403. doi: 10.1002/ece3.3035

39. Mohr KI (2018) Diversity of Myxobacteria-We Only See the Tip of the Iceberg. Microorganisms 6. doi: 10.3390 /microorganisms 6030084

40. Reichenbach H (1999) The ecology of the myxobacteria. Environ Microbiol 1: 15-21. doi: 10.1046/j.1462-2920.1999.00016.x

41. Geisseler D, Horwath WR, Joergensen RG, Ludwig B (2010) Pathways of nitrogen utilization by soil microorganisms - A review. Soil Biology and Biochemistry 42: 2058-2067. doi:

10.1016/j.soilbio.2010.08.021

42. Y CB, M D (1994) Isolated fibrils rescue cohesion and development in the Dsp mutant of Myxococcus xanthus. \%J Journal of bacteriology 176.

43. Kim SH, Ramaswamy S, Downard J (1999) Regulated exopolysaccharide production in Myxococcus xanthus. Journal of Bacteriology 181: 1496-1507. doi: 10.1128/jb.181.5.1496-1507.1999

44. Treuner-Lange A, Ward MJ, Zusman DR (2001) Pph1 from Myxococcus xanthus is a protein phosphatase involved in vegetative growth and development. Molecular Microbiology 40: 126-140. doi: 10.1046/j.1365-2958.2001.02362.x

45. Wang J, Hu W, Lux R, He X, Li Y, Shi W (2011) Natural Transformation of Myxococcus xanthus. Journal of Bacteriology 193: 2122-2132. doi: 10.1128/jb.00041-11

46. Qiu Z, Li Y, Zhang Y, Gong G, Zhang Y, Wang B (2003) Influences of Seawater lons on the Growth, Differerentiation of a Sait-Tolerant Myxobacterium Myxococcus fulvus HW-1. Journal of Mirobiology 23: 8-11.

47. Regentin R, Frykman S, Lau J, Tsuruta H, Licari P (2003) Nutrient regulation of epothilone biosynthesis in heterologous and native production strains. Applied Microbiology and Biotechnology 61: 451-455. doi: 10.1007/s00253-003-1263-1

48. Zengler K, Zaramela LS (2018) The social network of microorganisms - how auxotrophies shape complex communities. Nature Reviews Microbiology 16: 383-390. doi: 10.1038/s41579-018-0004-5

49. Wrótniak-Drzewiecka W, Brzezińska AJ, Dahm H, Ingle AP, Rai M (2015) Current trends in myxobacteria research. Annals of Microbiology 66: 17-33. doi: 10.1007/s13213-015-1104-3

50. Crutsinger GM, Collins MD, Fordyce JA, Gompert Z, Nice CC, Sanders NJ (2006) Plant genotypic diversity predicts community structure and governs an ecosystem process. Science 313: 966-968. doi: 10.1126/science.1128326

51. Scherber C, Eisenhauer N, Weisser WW, Schmid B, Voigt W, Fischer M, Schulze ED, Roscher C, Weigelt A, Allan E, Bessler H, Bonkowski M, Buchmann N, Buscot F, Clement LW, Ebeling A, Engels C, Halle S, Kertscher I, Klein AM, Koller R, Konig S, Kowalski E, Kummer V, Kuu A, Lange M, Lauterbach D, Middelhoff C, Migunova VD, Milcu A, Muller R, Partsch S, Petermann JS, Renker C, Rottstock T, Sabais A, Scheu S, Schumacher J, Temperton VM, Tscharntke T (2010) Bottom-up effects of plant 
diversity on multitrophic interactions in a biodiversity experiment. Nature 468: 553-556. doi: $10.1038 /$ nature09492

52. Yang JW, Wu W, Chung CC, Chiang KP, Gong GC, Hsieh CH (2018) Predator and prey biodiversity relationship and its consequences on marine ecosystem functioning-interplay between nanoflagellates and bacterioplankton. ISME J 12: 1532-1542. doi: 10.1038/s41396-018-0111-3

53. Morgan AD, MacLean RC, Hillesland KL, Velicer GJ (2010) Comparative Analysis of Myxococcus Predation on Soil Bacteria. Applied and Environmental Microbiology 76: 6920-6927. doi: 10.1128/aem.00414-10

\section{Tables}

Due to technical limitations, table 1 is only available as a download in the Supplemental Files section.

\section{Figures}
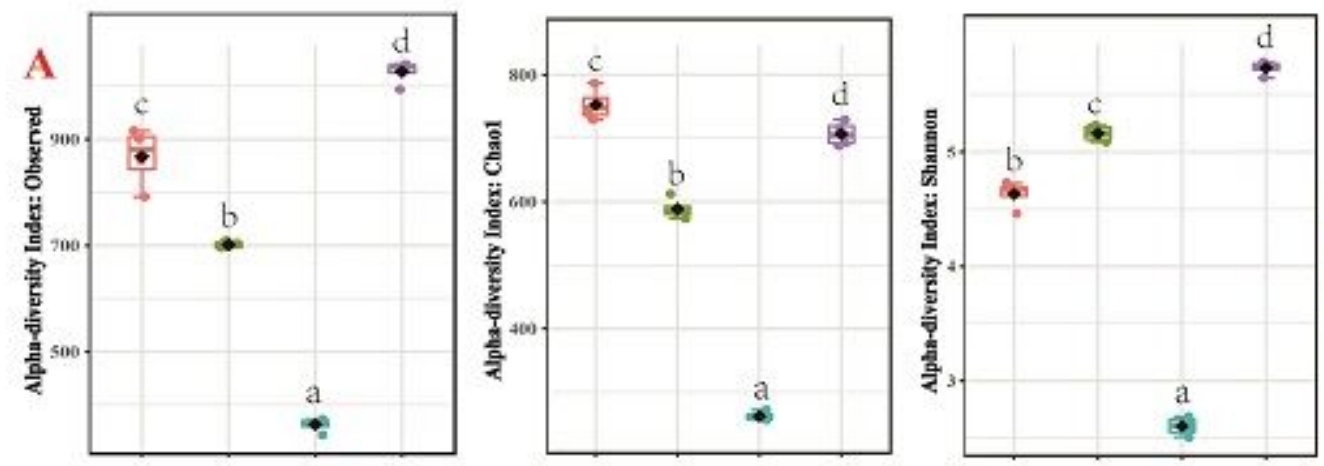

\section{CLASS}

Chicken manure

Ev Cow dung

Swine manure

$\$$ Wormcast
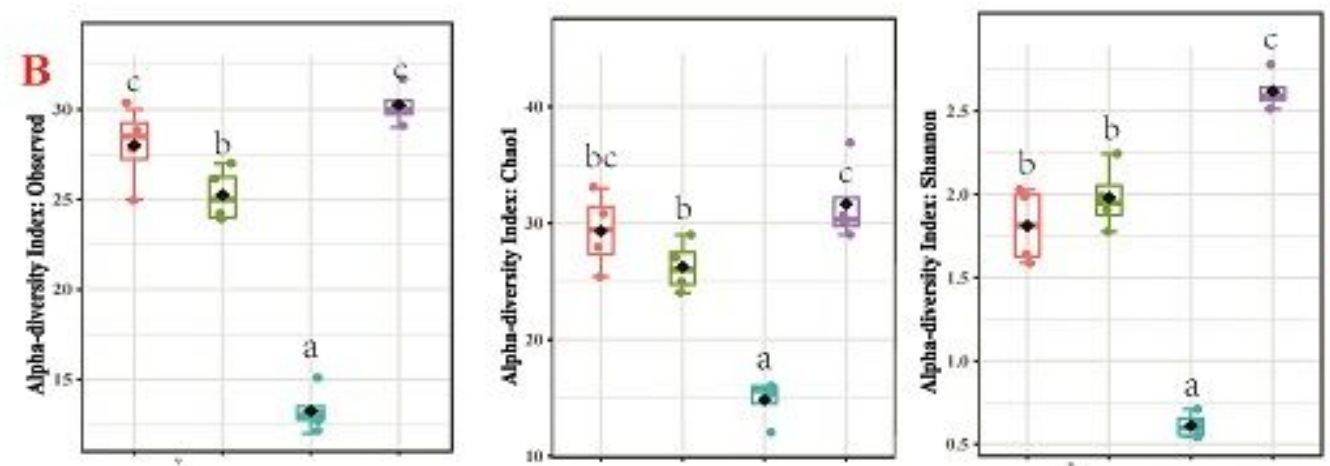

CLASS

Chicken manure

형 Cow dung

团 Swine manure

E Wormeast

\section{Figure 1}

a-diversity of bacteria (A) and myxobacteria (B) communities in four compost manures. 

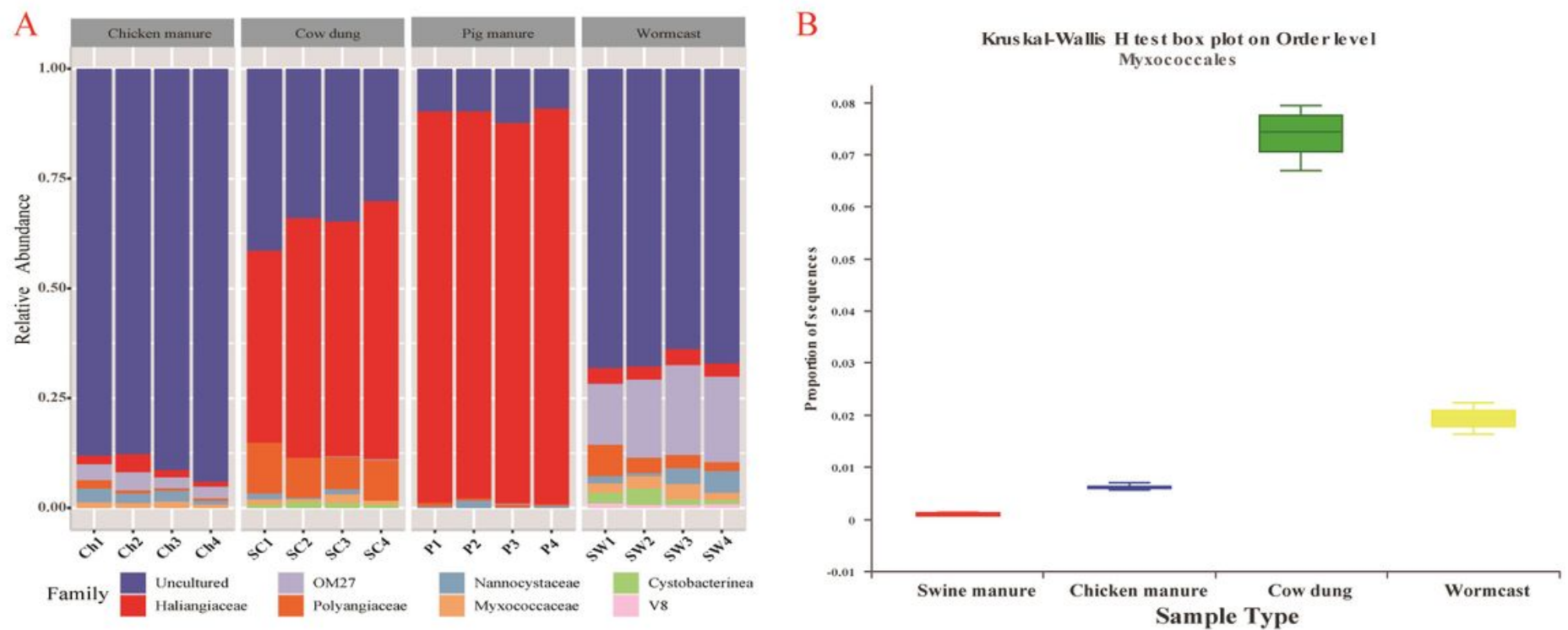

Figure 2

Myxobacteria community composition (A) and distribution (B) among the four compost manures 

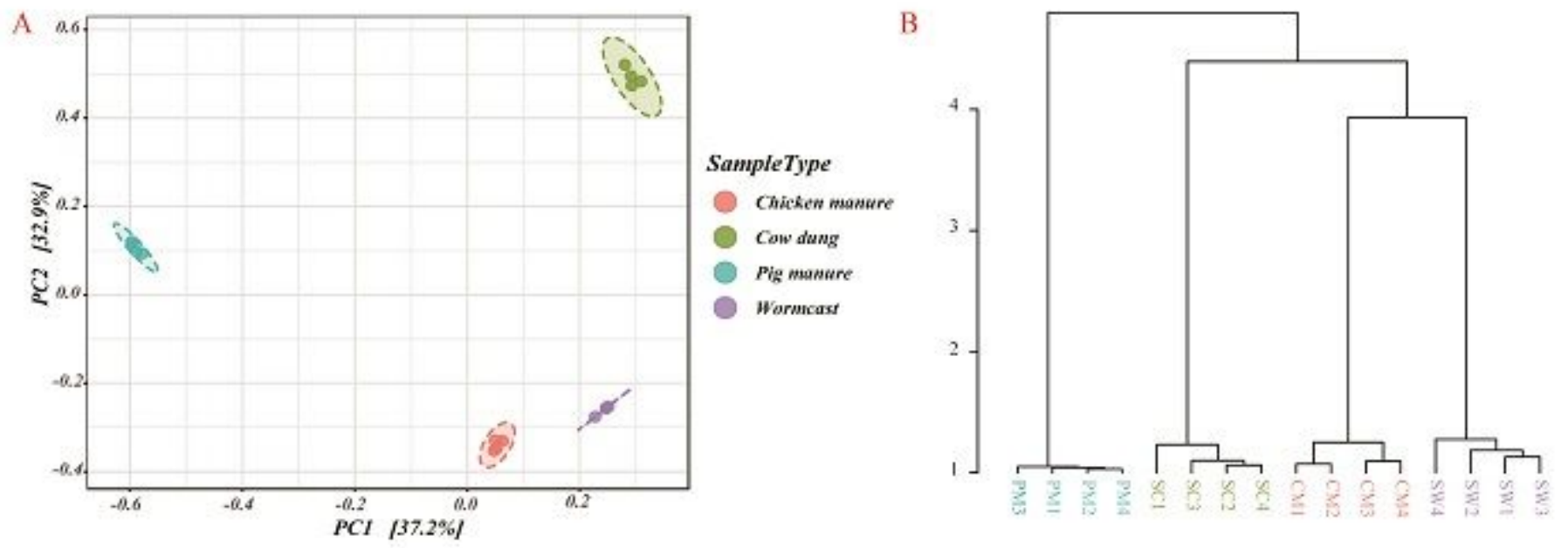

\section{Figure 3}

Principal coordinate analysis (A, PCoA) and hierarchical cluster tree (B) of myxobacteria communities (calculated based on Bray-Curtis distances). CM: chicken manure, CD: Cow dung, SM: swine manure and WC: wormcast 

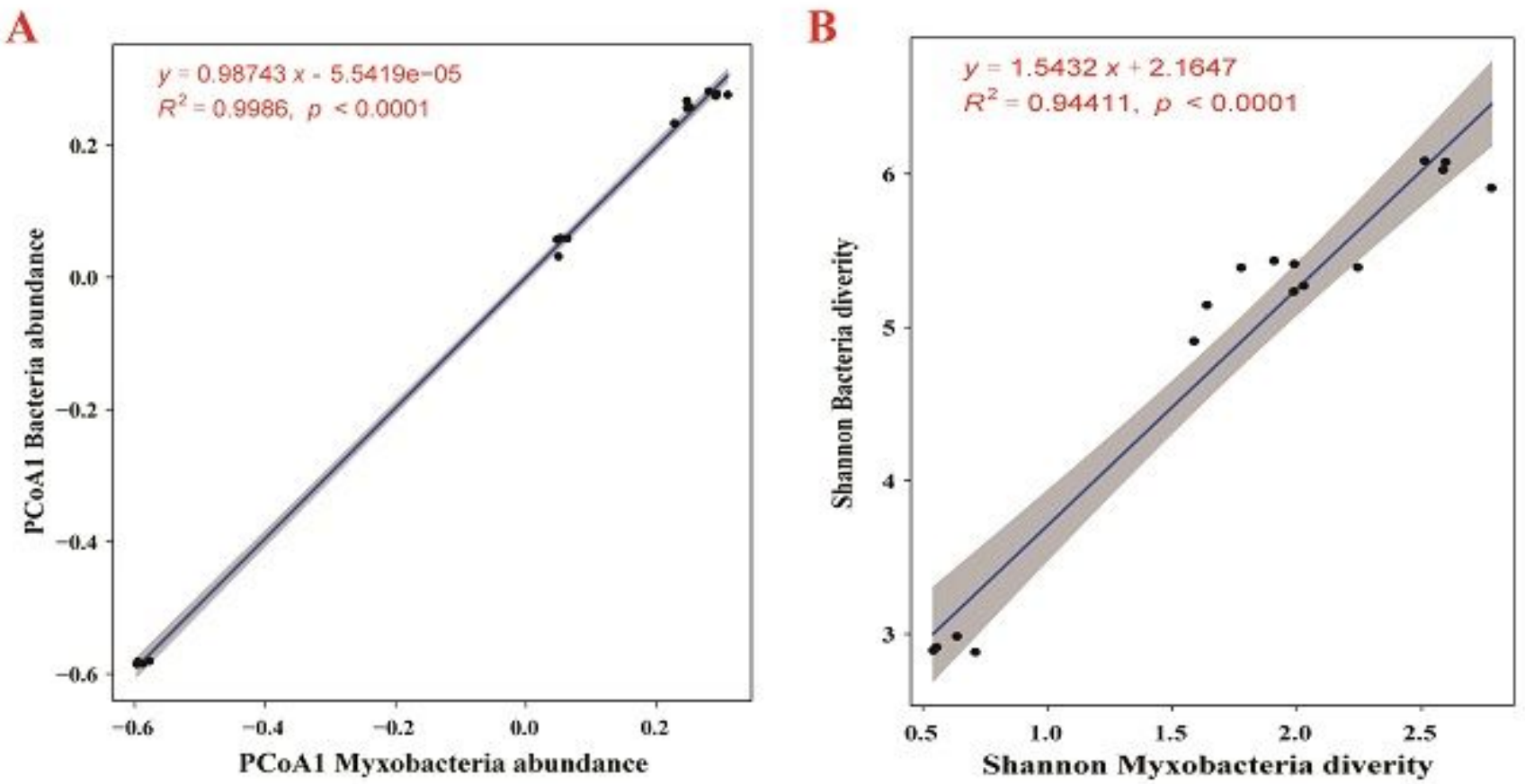

Figure 4

Relationship between myxobacteria and bacterial community abundance (A) and diversity (B) within four types of compost manure 


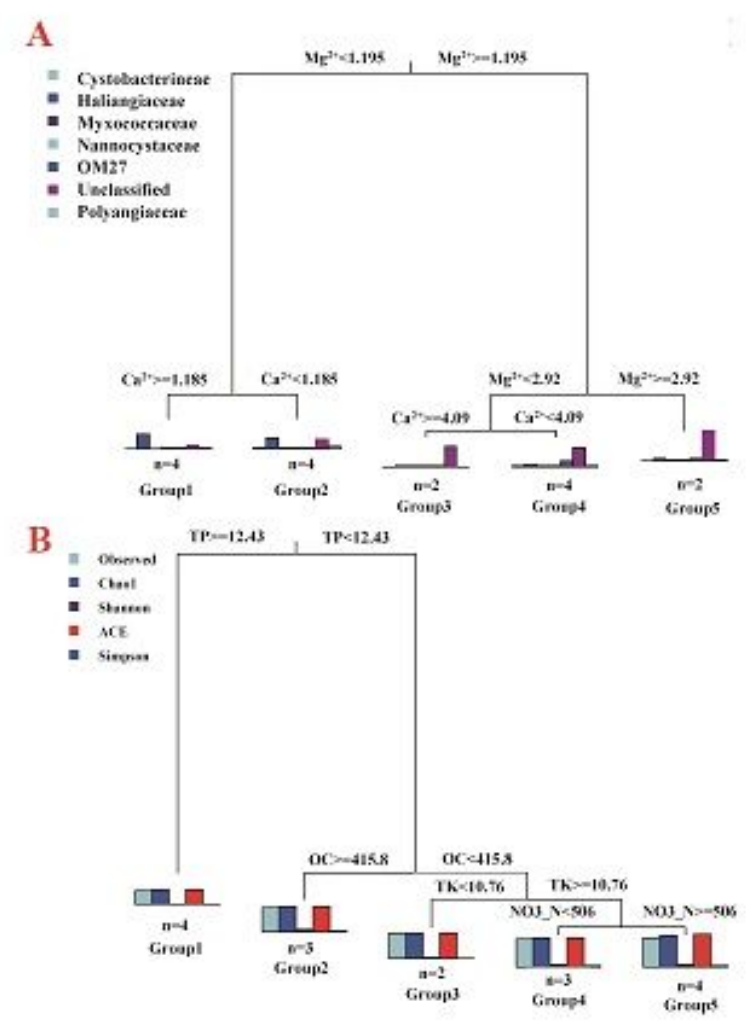

\section{Figure 5}

Multivariate regression tree (MRT) analysis of the correlation between myxobacteria composition (A) and diversity (B), and environmental factors. A: The bar plots illustrate the relative abundance of each order, and the bar plots represent the community composition dynamics among the splits. B: Diversity indices, including Observed OTU richness, Chao1, Shannon, ACE, and Simpson index, standardized for MRT analysis. Bar plots show the multivariate means of diversity among each split. The numbers under the bar are the numbers of samples in each group. TP: total phosphorus, OC: organic carbon, TK: total potassium, NO3--N: nitrate nitrogen. 
A

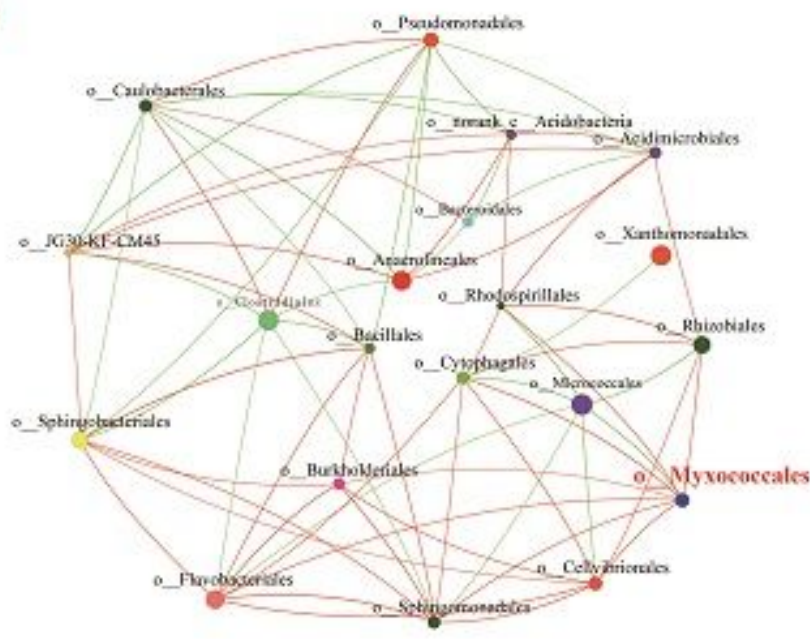

B

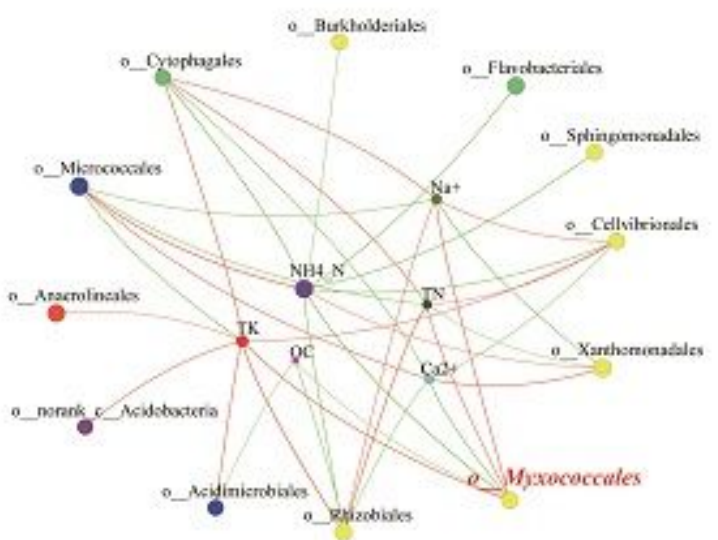

Figure 6

Distribution of predatory myxobacteria in different compost manures. Single (6A) and two-factor (6B) correlation network analysis at the order level. A network graph was constructed to illustrate positive or negative correlation between different bacterial orders. A red link indicates a positive correlation between two individual nodes, whereas a green link indicates a negative correlation. Different nodes represent different bacteria orders or environmental factors. TN: total nitrogen, OC: organic carbon, TK: total potassium, $\mathrm{NH} 4+-\mathrm{N}$ : ammonium nitrogen. 


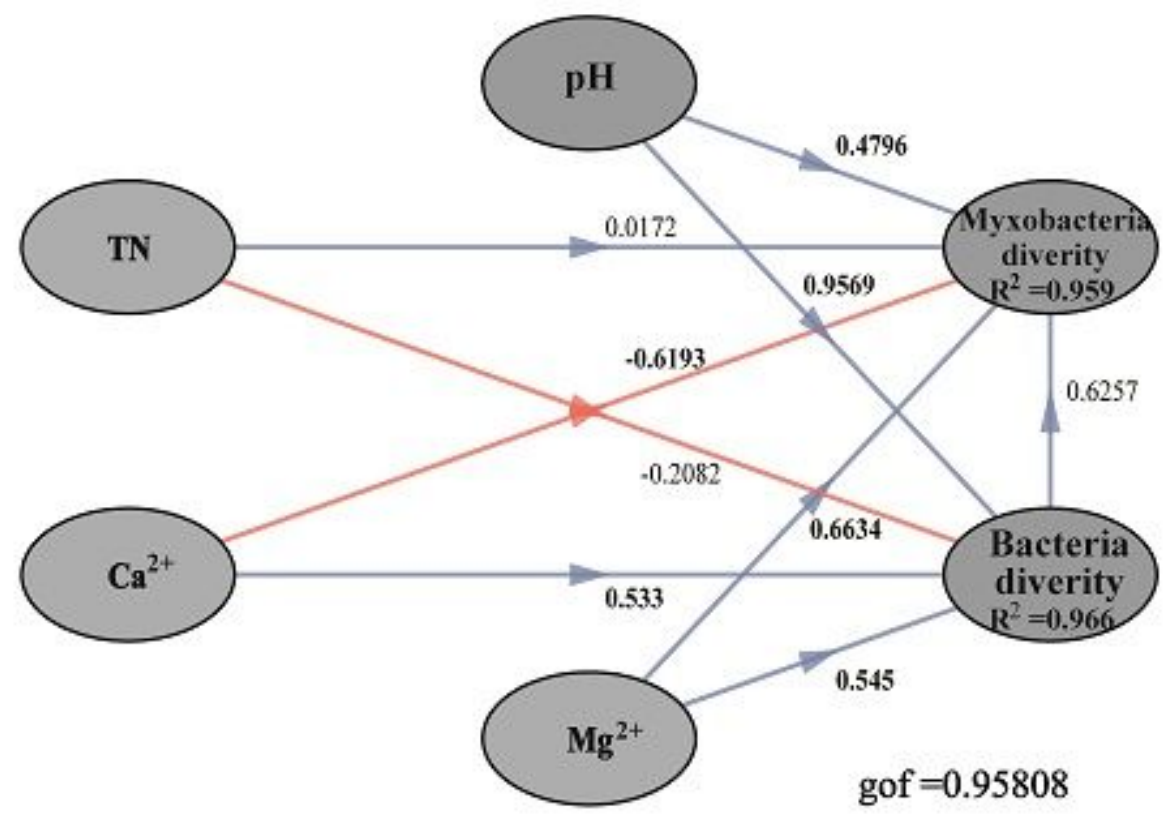

Figure 7

Structural equation models (SEMs) showing the effects of $\mathrm{pH}$, total nitrogen $(\mathrm{TN})$, calcium ions $(\mathrm{Ca} 2+)$, magnesium ions (Mg2+), and bacterial diversity on myxobacteria diversity. Values on the arrows represent the path coefficients. Red and blue lines indicate the significant $(P<0.05)$ and non-significant $(P>0.05)$ relationships, respectively. The "gof" indicates the goodness of fit. R2 denotes the proportion of variance explained. Bacterial and myxobacteria community diversity are represented using a-diversity indices (Observed OTU richness, Chao1, and Shannon). 


\section{Supplementary Files}

This is a list of supplementary files associated with this preprint. Click to download.

- Table1.xlsx

- SupplementTable1.xlsx

- SupplementTable2.xlsx

- SupplementTable3.xlsx

- SupplementTable4.xlsx

- SupplementTable5.xlsx

- Supplementmaterial.pdf 